RAD Conference Proceedings, vol. 4, pp. 138-141, 2020

ISSN 2466-4626 (online) | DOI: 10.21175/RadProc.2020.29

www.rad-proceedings.org

\title{
TITANATE-BASED CERAMIC AS A MATRIX FOR CURIUM AND RARE EARTH ELEMENT FRACTION OF RADIOACTIVE WASTE IMMOBILIZATION
}

\author{
S.S. Danilov' ${ }^{1}$ A.V. Frolova1, S. E. Vinokurovi ${ }^{*}$, S.V. Yudintsev' ${ }^{2}$, B.F. Myasoedov ${ }^{1}$
}

${ }^{1}$ Vernadsky Institute of Geochemistry and Analytical Chemistry, Russian Academy of Sciences, Moscow, Russia ${ }^{2}$ Institute of Geology of Ore Deposits, Petrography, Mineralogy and Geochemistry of the Russian Academy of Sciences, Moscow, Russia

\begin{abstract}
The effective isolation of radioactive waste $(R W)$ from the environment is the main problem for the further development of nuclear power. The main phases in titanate-based ceramics are perovskite, rutile, zirconolite and murataite. Murataite grains have a zonal structure with high content of rare earth elements at the center of structure and low content of these at edges, that precludes their leaching in contact with a solution. Murataite-based ceramics containing simulated rare earth elements of high level waste $(H L W)$ were produced via melting of oxide mixtures in a resistance furnace at $1500^{\circ} \mathrm{C}$. All samples were composed of mainly murataite and minor perovskite, crichtonite, zirconolite, and pyrophanite/ilmenite phases. Thus, murataite is the dominant host phase for a sample containing zirconium oxide. All samples were analyzed by scanning electron microscopy with an energy dispersive X-ray spectroscopy. Elemental leaching rates from the ceramic with low perovskite content were lower by one order of magnitude then leaching rates for high perovskite content.
\end{abstract}

Keywords: Rare earth, murataite-based ceramics, perovskite, scanning electron microscopy, hydrolytic stability

\section{INTRODUCTION}

The two-component nuclear power generating system is based on the use of thermal and fast neutron reactors and it provides for the reprocessing of spent nuclear fuel (SNF) and partitioning of the resulting radioactive waste [1]. The newly developed technology for SNF reprocessing provides for the separation of americium for its subsequent transmutation, as well as for the production of a curium-rare earth elements fraction (Cm-REE fraction) for temporary storage or disposal in deep formations [2].

In the last decade, the possibility of actinide containing fractions solidification into crystalline matrices of various structures was considered [3-5]. Crystalline matrices have many advantages: high corrosion resistance, incorporation of HLW without the formation of additional soluble phases, the presence of natural analogues as evidence of their longterm stability in the geological environment [6].

One of such minerals is murataite - a natural mineral with a crystal chemical formula: $\mathrm{A}_{6} \mathrm{~B}_{12} \mathrm{C}_{4} \mathrm{TX}_{40}$, where $\mathrm{A}=\mathrm{Y}, \mathrm{Na} ; \mathrm{B}=\mathrm{Ti} ; \mathrm{C}=\mathrm{Fe} ; \mathrm{T}=\mathrm{Zn} ; \mathrm{X}=\mathrm{O}$, $\mathrm{F}(\mathrm{a}=14.89 \AA, \mathrm{Z}=4)$, this structure was initially found in the titanate ceramics containing HLW surrogate of the Savannah River Plant, USA [7]. The structure of murataite contains several cationic positions: A - distorted cube, B - octahedron, C - trigonal bipyramid and $\mathrm{T}$ - tetrahedron [8]. The properties of murataite phases make it possible to consider this mineral as a unified matrix for the incorporation of RW of various compositions. It was shown in the work [9] that the composition of ceramics: $55 \% \mathrm{TiO}_{2}, 10 \%$ $\mathrm{MnO}_{2}, 10 \% \mathrm{CaO}, 5 \% \mathrm{Al}_{2} \mathrm{O}_{3}, 5 \% \mathrm{Fe}_{2} \mathrm{O}_{3}, 5 \% \mathrm{ZrO}_{2}$ may incorporate waste of various chemical composition with a mass fraction of up to $10 \%$. Ceramics of such composition based on murataite can be obtained by melting of the initial powders composition with components of radioactive waste at a temperature of $1,300-1,600{ }^{\circ} \mathrm{C}$.

During the synthesis of some murataite-based matrices, compositions which also included phases with a perovskite structure were found [10]. Perovskite is also considered as promising for the disposal of RW. It accumulates radionuclides ( $\mathrm{Sr}$, actinides), fission products, technological impurities (for example, $\mathrm{Na}$ ).

In our work, we investigated the effect of the dominant crystalline phase on the matrix hydrolytic stability for the immobilization of the Cm-REE fraction of high-level waste of a closed nuclear fuel cycle.

\section{EXPERIMENTAL}

The composition of samples selected for the synthesis differs from the basic content of zirconium and titanium oxides: $55 \pm \mathrm{x} \% \mathrm{TiO} 2,10 \% \mathrm{MnO} 2,10 \%$ $\mathrm{CaO}, 5 \% \mathrm{Al}_{2} \mathrm{O} 3,5 \% \mathrm{Fe} 2 \mathrm{O} 3,5 \pm \mathrm{x} \% \mathrm{ZrO} 2$, where $\mathrm{x}=5$ (Table 1). Samples were obtained by melting in a muffle furnace at $1500{ }^{\circ} \mathrm{C}$ for 30 minutes in glassy carbon crucibles and cooling in a switched off furnace. Neodymium was used as a chemical analogue of

*vinokurov.geokhi@gmail.com 
trivalent actinides $\left(\mathrm{Am}^{3+}, \mathrm{Cm}^{3+}\right)$, and as one of the main components of HLW.

The samples were characterized by scanning electron microscopy (SEM) using a JSM-5610LV unit with energy dispersive X-ray spectrometer (EDX) JED2300 (25 kV Voltage, $1 \mathrm{nA}$ beam current, 1-3 $\mu \mathrm{m}$ probe diameter, $100 \mathrm{~s}$ pulse collection time, metals, oxides, and fluorides as standards). The samples for SEM/EDX analysis were polished using diamond paste, all SEM micrographs were generated in backscattering electron (BSE) mode.

Table 1. The estimated composition of the samples

\begin{tabular}{|c|c|c|c|c|c|c|c|}
\hline Sample & $\mathrm{Al}_{2} \mathrm{O}_{3}$ & $\mathrm{CaO}$ & $\mathrm{TiO}_{2}$ & $\mathrm{MnO}$ & $\mathrm{Fe}_{2} \mathrm{O}_{3}$ & $\mathrm{ZrO}_{2}$ & $\mathrm{Nd}_{2} \mathrm{O}_{3}$ \\
\hline \begin{tabular}{|l|} 
RE-1 \\
RE-2
\end{tabular} & 5 & 10 & \begin{tabular}{|l|}
60 \\
50
\end{tabular} & 10 & 5 & $\begin{array}{c}- \\
10\end{array}$ & \\
\hline
\end{tabular}

The hydrolytic stability of the samples was investigated in accordance with the GOST R 521262003 standard [11], close to the MCC-1 and MCC-2 tests [12]. Monolithic samples were placed in autoclaves with Teflon inserts, filled with bidistilled water and kept at 90 and $150^{\circ} \mathrm{C}$ (imitation of conditions for disposal of heat-generating waste). The solution was replaced on 1, 7, 14, 21, 28 days after the start of the experiment. The surface of the samples was calculated from their geometric dimensions. However, the actual area considering the porosity and uneven surfaces is larger then geometric area, so the leaching rate values represent the upper limit value.

The differential leaching rate of the i-th element for the $n$-th time interval $R_{n}, g /\left(\mathrm{cm}^{2} \cdot d a y\right)$, was calculated by the formula:

$$
\mathrm{R}_{\mathrm{n}}^{\mathrm{i}}=\frac{\mathrm{m}_{\mathrm{n}}^{\mathrm{i}}}{\mathrm{M}_{\mathrm{o}, \mathrm{n}}^{\mathrm{i}} \cdot \mathrm{S} \cdot \Delta \mathrm{t}_{\mathrm{n}}}
$$

where $\mathrm{m}^{\mathrm{i}} \mathrm{n}$ is the mass of the element leached in the $\mathrm{n}$ th time interval, $\mathrm{g} ; \mathrm{M}_{\mathrm{o}, \mathrm{n}}$ - mass concentration of an element in the sample at the beginning of the n-th period, $\mathrm{g} / \mathrm{g} ; \mathrm{S}$ is the surface area of the sample in contact with water, $\mathrm{cm}^{2} ; \Delta t_{n}$ is the duration of the $\mathrm{n}$-th leaching period between solution changes, days.

The mechanism of neodymium leaching from the matrix was evaluated according to the de Groot and van der Sloot model [13], which can be represented as an equation of linear dependence (2):

$$
\lg \mathrm{Y}_{\mathrm{i}}=A \lg t+\text { const }
$$

where $\mathrm{Y}_{\mathrm{i}}$ is the total release of element $\mathrm{i}$ from the sample during contact with water, $\mathrm{mg} / \mathrm{m}^{2} ; \mathrm{t}$ - contact time, days.

\section{RESULTS AND DISCUSSION}

According to SEM / EDS data (Fig. 1, table 2 and 3), the main phase in the RE-1 sample is perovskite $(\mathrm{P})$, and the content of murataite (M) does not exceed 5 vol.\%. RE-1 sample also contains phases with the structure of crichtonite $(\mathrm{Cr})$, pyrophanite $(\mathrm{P} / \mathrm{I})$, and rutile (R). Murataite phase dominates in sample RE-2, which also contains phases with the structure of zirconolite, perovskite, and crichtonite. The ideal formulas for these phases are: $(\mathrm{Ca}, \mathrm{Nd})(\mathrm{Ti}, \mathrm{Al}) \mathrm{O}_{3}$ (perovskite), $(\mathrm{Ca}, \mathrm{Nd})(\mathrm{Zr}, \mathrm{Ti})(\mathrm{Ti}, \mathrm{Al}, \mathrm{Fe})_{2} \mathrm{O}_{7}$ (zirconolite), $(\mathrm{Mn}, \mathrm{Fe}) \mathrm{TiO}_{3}$ $(\mathrm{Ca}, \mathrm{Nd})(\mathrm{Fe}, \mathrm{Mn}) 2 \mathrm{Ti}, \mathrm{Al})_{18} \mathrm{O}_{38}$

(pyrophanite) (Ca,Mn,Nd)6(Ti,Zr,Mn,Fe,Al) ${ }_{17} \mathrm{O}_{43}$ (murataite), $\mathrm{TiO} 2$ (rutile). Their real compositions are much more complicated due to isomorphic exchanges in the crystal structure. $\mathrm{Ca}^{2+}$ positions include large cations $\left(\mathrm{Mn}^{2+}\right.$, $\left.\mathrm{Fe}^{2+}, \mathrm{RE}^{3+}\right), \mathrm{Ti}^{4+}$ can be replaced by $\mathrm{Al}^{3+}, \mathrm{Fe}^{3+}, \mathrm{Zr}^{4+}$. An increase in the $\mathrm{TiO} 2$ content relative to the basic composition leads to an increase in the amount of perovskite and a decrease in the proportion of murataite in ceramics. The bulk of neodymium in sample RE-1 is accumulated in perovskite and to a lesser extent in crichtonite, in sample RE-2 it is concentrated in murataite and, to a lesser extent, in crichtonite.
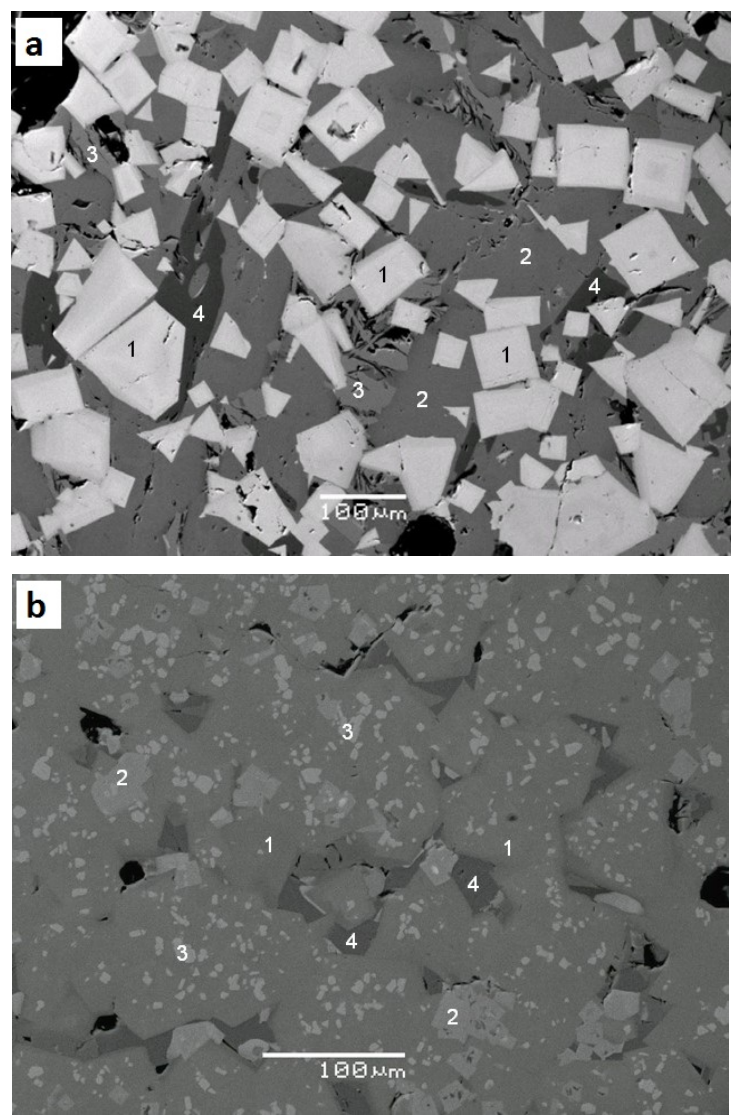

Figure 1. SEM image of sample RE-1(a) where perovskite (1), crichtonite (2), pyrophanite/ilmenite (3), rutile (4) and RE-2(b) where murataite (1), perovskite (2), zirconolite (3), crichtonite (4).

Table 2. Phase composition of samples

\begin{tabular}{|l|c|}
\hline Sample & Phases \\
\hline RE-1 & $\mathrm{P}>\mathrm{Cr}>\mathrm{P} / \mathrm{I} \sim \mathrm{R}>>\mathrm{M}$ \\
$\mathrm{RE}-2$ & $\mathrm{M}>\mathrm{Z} \sim \mathrm{P} \sim \mathrm{Cr}$ \\
\hline
\end{tabular}

where $\mathrm{P}$ - perovskite, $\mathrm{Cr}$ - crichtonite, $\mathrm{P} / \mathrm{I}$ - pyrophanite/ilmenite, $\mathrm{R}$ - rutile, $\mathrm{M}$ - murataite (all varieties), $\mathrm{Z}$ - zirconolite. 
S.S Danilov et al., Murataite based ceramic as a matrix..., RAD Conf. Proc., vol. 4, 2020, 138-141

Table 3. Phase composition in the atomic quantities of the elements

\begin{tabular}{|c|c|c|c|c|c|c|c|c|}
\hline \multirow{2}{*}{$\begin{array}{c}\text { Phas } \\
\text { e }\end{array}$} & $\mathrm{Al}$ & $\mathrm{Ca}$ & $\mathrm{Ti}$ & $\mathrm{Mn}$ & $\mathrm{Nd}$ & $\mathrm{Fe}$ & $\mathrm{Zr}$ & $\mathrm{O}$ \\
\hline & \multicolumn{7}{|c|}{$\mathrm{RE}-1$} \\
\hline $\mathrm{P}$ & 0.7 & 13.3 & 19.9 & - & 4.7 & - & & 61.4 \\
\hline $\mathrm{Cr}$ & 3.8 & 2.1 & 23.9 & 3.8 & 0.6 & 2.1 & & 63.7 \\
\hline $\mathrm{P} / \mathrm{I}$ & 0.2 & 0.2 & 19.4 & 13.9 & - & 5.2 & & 61.1 \\
\hline $\mathrm{R}$ & 0.2 & 0.1 & 33.1 & 0.1 & - & - & & 66.5 \\
\hline $\mathrm{M}$ & 6.3 & 3.9 & 18.0 & 7.1 & 0.3 & 2.9 & & 61.5 \\
\hline $\begin{array}{c}7 \\
\text { Phas }\end{array}$ & \multicolumn{7}{|c|}{$\mathrm{RE}-2$} \\
\hline $\mathrm{M}$ & 4.4 & 4.3 & 18.2 & 4.0 & 1.1 & 1.4 & 3.9 & 62.7 \\
\hline $\mathrm{P}$ & 2.9 & 11.9 & 18.9 & 1.4 & 2.9 & 0.9 & - & 61.1 \\
\hline $\mathrm{Z}$ & 2.9 & 4.6 & 17.5 & 3.5 & 1.4 & 1.0 & 6.0 & 63.1 \\
\hline $\mathrm{Cr}$ & 3.8 & 1.7 & 21.1 & 5.1 & 0.3 & 4.6 & 0.7 & 62.7 \\
\hline
\end{tabular}

\subsection{Hydrolytic stability}

The results of hydrolytic stability test are shown in Fig. 2a, b. It was found that the lowest differential leaching rate is characteristic to Ti. As the temperature rises to $150^{\circ} \mathrm{C}$, the elements leaching rate increases, except for Fe.

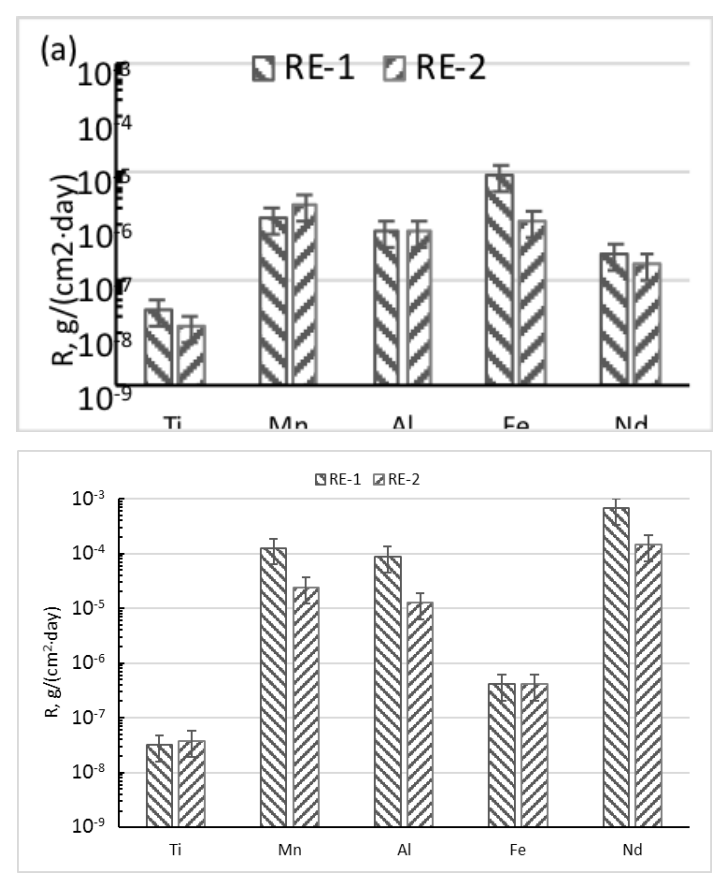

Figure 2. Differential leaching rate $\mathrm{R}\left(\mathrm{g} /\left(\mathrm{cm}^{2}\right.\right.$.day $\left.)\right)$, from samples RE-1 and RE-2 on the 28th day of interaction at $90^{\circ} \mathrm{C}(\mathrm{a})$ and $150^{\circ} \mathrm{C}(\mathrm{b})$.

Differential rates of $\mathrm{Nd}$ leaching on the 28 th day of contact are up to (2-3) $10^{-7} \mathrm{~g} /\left(\mathrm{cm}^{2}\right.$.day) (Fig. 2a). This is $1-3$ orders of magnitude lower than the rate of $\mathrm{Nd}$ leaching from aluminophosphate glasses under the same conditions [14]. In experiments at $150^{\circ} \mathrm{C}$, a falling of 2-3 orders of magnitude in the differential rate of $\mathrm{Nd}$ leaching is observed (Fig. 2b). The leaching rate at $150^{\circ} \mathrm{C}$ on the 28 th day is equal to $(1-7) \cdot 10^{-4}$ $\mathrm{g} /\left(\mathrm{cm}^{2} \cdot\right.$ day $)$.

The obtained data agree with the results of perovskite stability in comparison with the other actinide phases, consisting of perovskite, zirconolite, hollandite in the study of Synroc [15].

\subsection{Leaching mechanism}

To clarify the mechanism of leaching of neodymium from the murataite matrix at $90^{\circ} \mathrm{C}$ and $150^{\circ} \mathrm{C}$, a dependence was plotted according to the de Groot and van der Sloot model (Fig. 3).

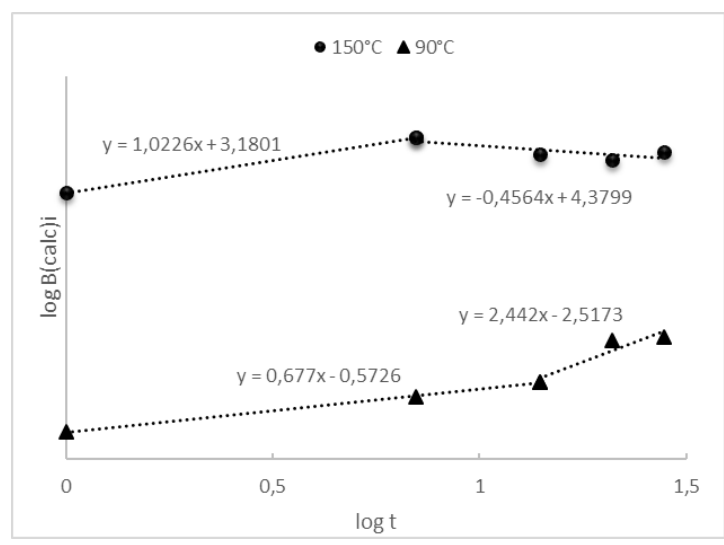

Figure 3. Logarithmic dependence of the Nd from the RE-2 sample yield on the time of contact with water

The slope of the resulting straight line corresponds to the predominant leaching mechanism. Earlier in works [16-19] it was shown that the values of the coefficient $\mathrm{A}$ in the equation correspond to the following mechanisms of leaching of elements: <0.35 leaching from the surface of the compound; 0.35-0.65 - diffusion from inner layers; > 0.65 - dissolution of the surface layer of the compound.

The main mechanism of neodymium leaching for both temperatures at the first moment of time is the dissolution of the surface, and then it changes to dissolution of the surface layer and leaching from the surface at temperatures of 90 and $150^{\circ} \mathrm{C}$, respectively (Fig. 3). Such differences in the mechanism of leaching after 7 days are probably related to the effect of temperature on the formation of the diffusion layer, rather than the composition of the matrix.

\section{CONCLUSION}

An increase in the $\mathrm{TiO}_{2}$ content due to the exclusion of $\mathrm{ZrO}_{2}$ from the matrix leads to an increase in the perovskite fraction and a decrease in the murataite fraction and, as a result, to an increase in the leaching rate. With an increase in temperature, the leaching rate increases for both samples by about three orders of magnitude to $(1-7) \cdot 10^{-4} \mathrm{~g} /\left(\mathrm{cm}^{2}\right.$.day) at $150^{\circ} \mathrm{C}$ versus $(2-3) \cdot 10^{-7} \mathrm{~g} /\left(\mathrm{cm}^{2} \cdot\right.$ day $)$ at $90^{\circ} \mathrm{C}$. The difference in the 
mechanism of leaching depending on the temperature for murataite ceramics was established.

Thus, the composition of the titanate-based ceramic in the range of 50-55 wt.\% $\mathrm{TiO}_{2}$ and $5-10 \%$ $\mathrm{ZrO} 2$ makes it possible to increase the more hydrolytically stable phases of murataite.

Acknowledgements: The reported study was funded by RFBR according to the research project No. 18-29-12032.

\section{REFERENCES}

1. N.N. Ponomarev-Stepnoi, "Two-Component Nuclear Power System with a Closed Nuclear Fuel Cycle Based on BN and VVER Reactors," Atomic Energy, vol. 120, no. 4, pp. 233-239, Aug. 2016 https://doi.org/10.1007/s10512-016-0123-x

2. Yu.M. Kulyako, D.A. Malikov, T.I. Trofimov, S.A. Perevalov, K.S. Pilyushenko, S.E. Vinokurov, B.F. Myasoedov, "Separation of Americium and Curium in Nitric Acid Solutions via Oxidation of Am(III) by Bismuthate and Perxenate Ions," Radiochemistry, vol. 62, no. 5, pp. 581-586, Jul. 2020 https://doi.org/10.1134/S1066362220050033

3. I.W. Donald, "Immobilization of radioactive materials as a ceramic wasteform" in Waste immobilization in glass and ceramic based hosts: radioactive, toxic and hazardous wastes. John Wiley \& Sons, 2010, pp. $185-212$.

4. S. V. Stefanovsky, S. V. Yudintsev "Titanates, zirconates, aluminates and ferrites as waste forms for actinide immobilization," Russian Chemical Reviews, vol. 85, no. 9, pp. 962-994, 2016. https://doi.org/10.1070/RCR4606

5. G.R. Lumpkin, "Ceramic host phases for nuclear waste remediation," in Experimental and Theoretical Approaches to Actinide Chemistry, CA, USA, John Wiley \& Sons Ltd, 2018, pp. 333-377.

6. A.A. Lizin, S.V. Tomilin, S.S. Poglyad, E.A. Pryzhevskaya, S.V. Yudintsev, S.V. Stefanovsky, "Murataite: a matrix for immobilizing waste generated in radiochemical reprocessing of spent nuclear fuel" Journal of Radioanalytical and Nuclear Chemistry, vol. 318, pp. 2363, 2018. https://doi.org/10.1007/s10967-018-6236-Z

7. P.E.D. Morgan, F.J. Ryerson, "A new "cubic" crystal compound," J. Mater. Sci. Lett., vol. 1, pp. 351-352, 1982.

8. N.P. Laverov, S.V. Yudintsev, S.V. Stefanovsky, B.I. Omel'yanenko, B.S. Nikonov, "Murataite as a universal matrix for immobilization of actinides," Geology of Ore Deposits, vol.48, no. 5, pp. 335-356, 2006. https://doi.org/10.1134/S1075701506050011

9. S.V. Stefanovsky, S.V Yudintsev, B.S. Nikonov, B.I. Omel'yanenko, O.I. Stefanovsky, Patent of RF 2315381 from 22.05.2006 (2008).

Retrieved from:

https://patents.google.com/patent/RU2643362C1/ru
10. N.P. Laverov, S.V. Yudintsev, S.V. Stefanovsky, B.S. Nikonov, B.I. Omel'yanenko, "Murataite matrices for actinide wastes," Radiochemistry, vol. 53, no.3, pp. 229-243, 2011. https://doi.org/10.1134/S1066362211030027

11. ГОСТ Р 52126-2003. Отходы радиоактивные. Определение химической устойчивости отвержденных высокоактивных отходов методом длительного выщелачивания. М.: Госстандарт России. Т. 3, 2003.

(Radioactive waste. Determination of the chemical stability of solidified high-level waste by the long-term leaching method, Moscow: Gosstandart of Russia, GOST R. 52126, Jul. 1, 2004.)

12. W.E. Lee, M.I. Ojovan, M.C. Stennett, N.C. Hyatt, "Immobilisation of radioactive waste in glasses, glass composite materials and ceramics," Advances in Applied Ceramics, vol. 105, no. 1, pp. 3-12, 2006. https://doi.org/10.1179/174367606X81669

13. G.J. de Groot, H.A. van der Sloot, "Determination of leaching characteristics of waste materials leading to environmental product certification" in Stabilization and Solidification of Hazardous, Radioactive, and Mixed Wastes: $2^{\text {nd }}$ volume, ASTM International, 1992, pp. 149-170.

14. S.V. Stefanovsky, O.I. Stefanovsky, S.S. Danilov, M.I. Kadyko "Phosphate-based glasses and glass ceramics for immobilization of lanthanides and actinides," Ceramics International, vol. 45, no. 7, pp. 9331-9338, 2019. https://doi.org/10.1016/j.ceramint.2018.06.208

15. A. E. Ringwood, S. E. Kesson, K. D. Reeve, D. M. Levins E. J. Ramm, "Crystalline Waste Forms. Synroc," in Radioactive Waste Forms for the Future, Elsevier, Netherlands, 1988, ch. 2, pp. 233-334.

16. S.A. Kulikova, S.S Danilov, K.Y. Belova, A.A. Rodionova, S.E. Vinokurov, "Optimization of the Solidification Method of High-Level Waste for Increasing the Thermal Stability of the Magnesium Potassium Phosphate Compound," Energies, vol. 13, no. 15 , article no. $3789,2020$. https://doi.org/10.3390/en13153780

17. D.H. Moon, D. Dermatas, "An evaluation of lead leachability from stabilized/solidified soils under modified semi-dynamic leaching conditions," Engineering Geology, vol.85, no. 1-2, pp. 67-74, 2006. https://doi.org/10.1016/i.enggeo.2005.09.028

18. J. Torras, I. Buj, M. Rovira, J. de Pablo, "Semi-dynamic leaching tests of nickel containing wastes stabilized/solidified with magnesium potassium phosphate cements," Journal of Hazardous Materials, vol. 186, no. 2-3, pp. 1954-1960, 2011. https://doi.org/10.1016/j.jhazmat.2010.12.093

19. Q. Xue, P. Wang, J.-S. Li, T.-T. Zhang, S.-Y. Wang, "Investigation of the leaching behavior of lead in stabilized/solidified waste using a two-year semidynamic leaching test," Chemosphere, vol. 166, pp. 1-7, 2017.

https://doi.org/10.1016/j.chemosphere.2016.09.059 